\title{
Review Article \\ Therapeutic Targeting of Fibroblast Growth Factor Receptors in Gastric Cancer
}

\author{
Mikito Inokuchi, ${ }^{1}$ Yoshitaka Fujimori, ${ }^{1}$ Sho Otsuki, ${ }^{1}$ Yuya Sato, ${ }^{1}$ \\ Masatoshi Nakagawa, ${ }^{1}$ and Kazuyuki Kojima ${ }^{2}$ \\ ${ }^{1}$ Department of Surgical Oncology, Tokyo Medical and Dental University, 1-5-45, Yushima, Bunkyo-ku, Tokyo 113-8519, Japan \\ ${ }^{2}$ Department of Minimally Invasive Surgery, Tokyo Medical and Dental University, 1-5-45, Yushima, Bunkyo-ku, Tokyo 113-8519, Japan
}

Correspondence should be addressed to Mikito Inokuchi; m-inokuchi.srg2@tmd.ac.jp

Received 16 September 2014; Revised 7 December 2014; Accepted 8 December 2014

Academic Editor: Chunping Jiang

Copyright (C) 2015 Mikito Inokuchi et al. This is an open access article distributed under the Creative Commons Attribution License, which permits unrestricted use, distribution, and reproduction in any medium, provided the original work is properly cited.

Chemotherapy has become the global standard treatment for patients with metastatic or unresectable gastric cancer (GC), although outcomes remain unfavorable. Many molecular-targeted therapies inhibiting signaling pathways of various tyrosine kinase receptors have been developed, and monoclonal antibodies targeting human epidermal growth factor receptor 2 (HER2) have become standard therapy for HER2-positive GC. An inhibitor of vascular endothelial growth factor receptor 2 or MET has also produced promising results in patients with GC. Fibroblast growth factor receptors (FGFR) play key roles in tumor growth via activated signaling pathways in GC. Genomic amplification of FGFR2 leads to the aberrant activation found in GC tumors and is related to survival in patients with GC. This review discusses the clinical relevance of FGFR in GC and examines FGFR as a potential therapeutic target in patients with GC. Preclinical studies in animal models suggest that multitargeted tyrosine kinase inhibitors (TKIs), including FGFR inhibitor, suppress tumor cell proliferation and delay tumor progression. Several TKIs are now being evaluated in clinical trials as treatment for metastatic or unresectable GC harboring FGFR2 amplification.

\section{Introduction}

Gastric cancer (GC) is the second leading cause of cancerrelated mortality, with 738,000 deaths per year [1]. Median overall survival was only 10 to 13 months in patients with metastatic or unresectable GC who received combined chemotherapy with cytotoxic agents [2-4].

Aberrant or oncogenic activation of receptor tyrosine kinase (RTK) is involved in carcinogenesis or tumor progression. Inhibition of signaling pathways of RTK is most intensively pursued as an anticancer target. Trastuzumab, a monoclonal antibody against human epidermal growth factor receptor 2 (HER2/ERBB2), was the first RTK-targeting agent approved for the indication of unresectable or metastatic GC worldwide [5]. However, several agents targeting epidermal growth factor receptor (EGFR) provided no additional benefits in clinical trials [6-8]. Bevacizumab, a monoclonal antibody targeting vascular endothelial growth factor(VEGF-) A, which activates VEGF receptor- (VEGFR-) 1 and VEGFR-2, provided significant benefits in terms of progression-free survival (PFS), but not overall survival (OS) [9]. Ramucirumab is a monoclonal antibody targeting the extracellular domain of VEGFR-2. Ramucirumab as secondline chemotherapy prolonged overall survival $[10,11]$ and was recently approved for the indication of unresectable or metastatic GC. Rilotumumab is a monoclonal antibody designed to inhibit binding of HGF to c-MET. Its additive effect was clinically significant in GC with high c-MET expression [12].

Fibroblast growth factor receptors (FGFRs) are one of the RTK families that belong to the immunoglobulin (Ig) superfamily [13]. Binding of fibroblast growth factors (FGFs) with high-affinity to FGFR results in kinase activation of downstream signaling pathways. The FGFR family consists of 5 receptors, named FGFR1 to FGFR5. The extracellular regions of FGFRs comprise 3 extracellular Ig-like domains (I-III), a single transmembrane domain, and the cytoplasmic tyrosine kinase domains TK1 and TK2. However, FGFR5 
TABLE 1: FGFR protein expressions on immunohistochemical analysis and clinical outcomes in GC.

\begin{tabular}{|c|c|c|c|c|c|c|}
\hline & $n$ & $\begin{array}{l}\text { Definition of } \\
\text { positivity }\end{array}$ & $\begin{array}{l}\text { Positive } \\
\text { case } \%\end{array}$ & $\begin{array}{c}\text { Relation to } \\
\text { clinicopathological } \\
\text { factors }\end{array}$ & Relation to survival & Reference \\
\hline FGFR1 & 222 & $\begin{array}{l}\text { Scoring system of } \\
\text { intensity + extensity }\end{array}$ & 29 & $\mathrm{~T}, \mathrm{~N}, \mathrm{M}$, stage & Worse & {$[19]$} \\
\hline \multirow{4}{*}{ FGFR2 } & 950 & $2+$ or $3+,>50 \%$ & 31 & T, N, M, stage & Worse & {$[22]$} \\
\hline & 222 & $\begin{array}{l}\text { Scoring system of } \\
\text { intensity + extensity }\end{array}$ & 51 & $\mathrm{~T}, \mathrm{~N}, \mathrm{M}$, stage & Worse & {$[19]$} \\
\hline & 136 & $\begin{array}{l}\text { Stronger than normal } \\
\text { epithelium }\end{array}$ & 31 & $\begin{array}{l}\text { T, peritoneal } \\
\text { Dissemination, } \\
\text { diffuse type }\end{array}$ & Worse & {$[20]$} \\
\hline & 49 & $\begin{array}{c}\text { Stronger than normal } \\
\text { epithelium }\end{array}$ & 41 & $\begin{array}{c}\text { Stage } \\
\text { Undifferentiated type }\end{array}$ & Worse & {$[21]$} \\
\hline FGFR3 & 222 & $\begin{array}{c}\text { Scoring system of } \\
\text { intensity }+ \text { extensity }\end{array}$ & 64 & NA & NA & {$[19]$} \\
\hline \multirow[t]{2}{*}{ FGFR4 } & 222 & $\begin{array}{c}\text { Scoring system of } \\
\text { intensity + extensity } \\
\text { score }\end{array}$ & 79 & $\mathrm{~T}, \mathrm{~N}, \mathrm{M}$, stage & Worse & {$[19]$} \\
\hline & 94 & $3+,>10 \%$ & 38 & NA & Worse & {$[23]$} \\
\hline
\end{tabular}

T: tumor depth; N: lymph-node metastasis; M: distant metastasis; NA: not assisted.

lacks an intracellular tyrosine kinase domain. The extracellular Ig-II and Ig-III domains are the FGF ligand-binding sites. Alternative splicing of Ig-III occurs in FGFRs 1-3, creating IIIb and IIIc variants of the receptors with diverse ligandbinding specificities that are expressed in a tissue-specific manner [14-16]. Binding of FGFs to FGFRs induces receptor dimerization, conformational changes within the FGFR structure, and phosphorylation of tyrosines in the intracellular part of the receptor, including the kinase domain and the C-terminus [17]. Subsequent downstream signaling is activated in two main pathways via the intracellular receptor substrates FGFR substrate 2 (FRS2) and phospholipase Cg, leading ultimately to upregulation of the Ras-dependent mitogenactivated protein kinase (MAPK)/extracellular signal-regulated kinase (ERK) and Ras-independent phosphoinositide 3kinase (PI3K)/Akt signaling pathways [18]. The other signaling pathway, dependent on signal transducer and activator of transcription (STAT), is activated by FGFRs [14].

\section{Clinical Analysis of Expression or Genomic Alteration of FGFR in GC}

The results of immunohistochemical analyses of FGFRs are summarized in Table 1 . We previously showed that protein overexpression of FGFR1, FGFR2, and FGFR4 is significantly associated with tumor depth, lymph-node metastasis, tumor stage, and poorer survival in GC, while FGFR3 is not [19]. Others have shown that overexpression of K-sam, a FGFR2 homologue, is significantly related to pathologically undifferentiated or diffuse-type GC $[20,21]$. Nagatsuma et al. reported that FGFR2 overexpression is significantly associated with tumor depth, lymph-node metastasis, and tumor stage in a larger analysis [22]. Moreover, patients with FGFR2 overexpression had a significantly higher incidence of peritoneal or lymph-node recurrence and a significantly shorter survival than those without FGFR2 overexpression. Ye et al. showed that FGFR4 is not associated with any clinicopathological factors or with survival, although patients with far advanced GC and FGFR4 overexpression had significantly worse survival [23]. The mRNA expression of FGFR1, FGFR2, or FGFR4 was upregulated in GC as compared with that in normal tissues, although FGFR3 mRNA was barely detectable in normal as well as cancer tissue [24].

Studies of FGFR genomic alterations are summarized in Table 2. FGFR2 amplification is a well-known phenomenon in GC. The frequency of FGFR2 amplification on comparative genomic hybridization had been reported to be $7 \%$ ( 2 of 30 ) in GC in one study and 16\% (3 of 19) in diffuse-type GC in another $[25,26]$. In a study using Southern blot analysis, the frequency of FGFR2 amplification was 5\% (3 of 57) [27]. Betts et al. reported that FGFR2 amplification was detected on fluorescence in situ hybridization (FISH) analysis in 1.8\% ( 3 of 171) of GCs, and survival was very poor in three patients who had tumors with FGFR2-amplification [28]. In a study by Jung et al., FGFR2 amplification was detected on FISH in 4.5\% (14 of 313) of GCs and was significantly associated with the depth of tumor invasion, lymph-node metastasis, distant metastasis, tumor stage, and poorer survival [29]. In that study, FGFR2 amplification was not detected in papillary or well-differentiated subtypes of GC. Das et al. reported that FGFR2 amplification was found in $7.3 \%$ (10 of 137) of patients, while FGFR2 deletion was detected in $5.8 \%$ (8 of 137), and patients with FGFR2-amplified GC had worse survival than those with FGFR2-deleted GC [30]. Interestingly, they showed that not only FGFR2 amplification but also deletion was more common in undifferentiated type than in differentiated type. In an international multicenter study using FISH, the presence of FGFR2 amplification did not differ appreciably among three countries: 7.4\% (30 of 408) in the UK, 4.6\% (9 of 197) in China, and 4.2\% (15 of 356) in 
TABLE 2: FGFR gene alterations in GC.

\begin{tabular}{|c|c|c|c|c|c|c|c|}
\hline & Method & $n$ & $\begin{array}{l}\text { Positive expression } \\
\text { definition }\end{array}$ & $\%$ & $\begin{array}{c}\text { Relation to } \\
\text { clinicopathological factors }\end{array}$ & Relation to survival & Reference \\
\hline \multirow{7}{*}{$\begin{array}{l}\text { FGFR2 } \\
\text { amplification }\end{array}$} & FISH & 961 & $\begin{array}{c}F G F R 2 / C E P-10 \text { ratio } \geq 2 \\
\text { or } F G F R 2 \text { gene clusters } \\
\text { in } \geq 10 \%\end{array}$ & 5.6 & $\mathrm{~N}$ & Worse & {$[31]$} \\
\hline & FISH & 313 & $\begin{array}{l}F G F R 2 / C E P-10 \text { ratio } \geq 2 \\
\text { or FGFR2 gene clusters }\end{array}$ & 4.5 & $\mathrm{~T}, \mathrm{~N}, \mathrm{M}$, stage & Worse & {$[29]$} \\
\hline & FISH & 171 & FGFR $2 / C E P-10$ ratio $\geq 2$ & 1.8 & ND & Worse & [28] \\
\hline & FISH & 137 & $F G F R 2 / C E P-10$ ratio $\geq 2$ & 7.3 & Undifferentiated type & Worse & {$[30]$} \\
\hline & RT-PCR & 267 & FGFR2 $>5$ copies & 4.1 & NA & worse & {$[32]$} \\
\hline & SNP microarray & 193 & GISTIC algorithm & 9.3 & NA & NA & {$[33]$} \\
\hline & SNP microarray & 100 & GISTIC algorithm & 3.0 & ND & Not investigated & {$[34]$} \\
\hline FGFR4 SNIP & PCR-RFLP & 103 & Arg388 allele & 57 & NA & Worse & {$[36]$} \\
\hline FGFR1 mutation & Whole-exome sequence & 138 & & 2.2 & ND & ND & [37] \\
\hline
\end{tabular}

FISH: fluorescence in situ hybridization; RT-PCR: reverse-transcription polymerase chain reaction; SNP: single nucleotide polymorphism; PCR-RFLP: polymerase chain reaction-restriction fragment length polymorphism analysis; CEP: chromosome enumeration probe; GISTIC: the genomic identification of significant targets in cancer; T: tumor depth; N: lymph-node metastasis; M: distant metastasis; NA: not assisted; ND: not described.

Korea [31]. In each country, patients with FGFR2-amplified GCs had worse survival than those with nonamplified GCs. In addition, 24.1\% of FGFR2-amplified GCs displayed intratumoral heterogeneity within multiple samples extracted from the same tumors on tissue microarray analysis. In the FISH studies mentioned above, FGFR2 gene amplification was determined on the basis of the presence of tight signals of FGFR2 clusters or a ratio of FGFR2 signals to chromosome enumeration probe-10 signals of 2.0 or higher.

Matsumoto et al. reported that FGFR2 amplification on copy number assay (more than 5 copies) was detected in $4.1 \%$ (11 of 267) of GCs, whereas amplification of other FGFRs was not detected [32]. Patients with FGFR2-amplified tumors had slightly but not significantly shorter survival than those with nonamplified tumors. In a comprehensive survey assessing genomic alterations of GCs by high-resolution single nucleotide polymorphism arrays, FGFR2 amplification was detected in $9.3 \%$ (18 of 193) of GCs, and coamplification of FGFR2 with EGFR, ERBB2, KRAS, or MET was rarely detected [33]. In that study, the overall survival of patients with FGFR2 amplification did not differ from that of patients with nonamplification, although the survival of patients with high mRNA expression of FGFR2 was significantly worse than that of patients with low mRNA expression of FGFR2 in the extended population. Wang et al. detected FGFR2 amplification in 3.0\% (3 of 100) of GCs on single nucleotide polymorphism (SNP) genotyping arrays [34]. In addition, two mutations of FGFR2 were identified in GC: a missense in exon IIIa and a splice site mutation in exon IIIc [35].

Among other FGFR genes, Ye et al. investigated the SNP of FGFR4 (Gly388 to Arg388) in GC samples and showed that $45 \%$ (46 of 103) of patients were heterozygous and 13\% (13 of 103) homozygous for Arg388 allele [36]. Patients with tumors in which FGFR4 Arg388 allele was found had significantly shorter survival, and the presence of FGFR4 Gly388Arg allele was an independent prognostic factor. FGFR1 somatic mutation on whole-exome sequencing was detected in 1.1\% (1 of 87 ) of diffuse type GCs and in $3.9 \%$ ( 2 of 51 ) of intestinal type GCs [37].

\section{Preclinical Studies of FGFR Inhibition in GC Cells}

FGFR2-amplified GC cell lines have high expression of FGFR2 protein or FGFR2 mRNA $[32,38]$. On the other hand, the promoter region of FGFR2 gene is highly methylated, and FGFR2 mRNA expression is markedly reduced in several GC cell lines (SNU-1, SNU-5, SNU-484, and SNU-638) [39]. FGFR2 mRNA expression was restorable by demethylation using 5-aza- $2^{\prime}$-deoxycytidine in cell lines with methylation of the promoter region of FGFR2, suggesting that aberrant hypermethylation of FGFR2 gene might lead to loss of FGFR2 expression.

Zhao et al. generated two effective monoclonal antibodies that recognize different epitopes on FGFR2: GAL-FR21, binding to only IIIb isoform of FGFR2, and GAL-FR22, binding to both IIIb and IIIc isoforms [40]. GAL-FR21 and GAL-FR22 blocked the binding of FGFs to FGFR2 IIIb, and GAL-FR21 inhibited FGF-induced phosphorylation of FGFR2. Both antibodies downregulated FGFR2 expression on SNU-16, an FGFR2-amplified GC cell line and effectively inhibited the growth of SNU-16 xenograft tumors.

GP369 is an FGFR2-IIIb-specific antibody and blocked phosphorylation of FGFR2, FRS2 tyrosine, and ERK in a GC cell line (SNU-16) overexpressing FGFR2-IIIb [41]. GP369 treatment potently inhibited the growth of SNU-16 xenograft tumors.

Small-molecule compounds fitting into the ATP-binding pockets of RTKs have been developed as anticancer drugs. PD173074 is a reversible inhibitor of FGFR and VEGFR. PD173074 blocks FGF2-induced angiogenesis [42] and also 
blocks mitogenesis of tumor cells via G1-arrest mediated by downregulation of cyclin D1 and cyclin D2 [43]. Treatment with PD173074 selectively and potently inhibited growth of FGFR2-amplified GC cell lines (KATOIII, SNU-16, and OCUM-2M), leading to a strong decrease in tumor cells in $S$ phase accompanied by an increase in tumor cells in the sub-G1 population [38]. In addition, prominent induction of poly(ADP-ribose) polymerase, a marker of caspase activation associated with apoptosis, was observed after treatment. EGFR family kinases might have been downstream targets of amplified FGFR2 in that study, because the increased expression of phosphorylated HER receptors was dependent on FGFR2. PD173074 was more effective in FGFR2-amplified GC cell lines (SNU-16, TU-KATOIII, HSC-43, and HSC-39) than in nonamplified cell lines (OCUM1, IM95, 58Aa1, and 44As3) on growth inhibition assays [32].

Ki23057, a small-molecule-acting FGFR and VEGFR autophosphorylation inhibitor, significantly suppressed the proliferation of scirrhous cancer cells (OCUM-2MD3 and OCUM-8), but not nonscirrhous cancer cells (MKN-7, MKN45, and MKN-74) [44]. Administration of Ki23057 prolonged survival in a mouse model of peritoneal dissemination prepared using OCUM-2MD3. Ki23057 mainly inhibited the downstream RAS-ERK signaling pathway rather than another PI3K-Akt pathway.

Cediranib (AZD2171) is also a broad-range tyrosine kinase inhibitor (TKI) and inhibits FGFR, VEGFR, PDGFR, and KIT, as well as VEGF-induced proliferation of human endothelial cells [45]. Cediranib completely inhibited the phosphorylation of FGFR2 and downstream targets, including FRS2, Akt, and MAPK, in GC cell lines (KATO-III and OCUM2M) that strongly expressed FGFR2-IIIb mRNA, and then significantly and dose-dependently inhibited tumor growth in KATO-III and OCUM2M tumor xenografts [46].

AZD4547 is a highly selective and potent ATP-competitive TKI of FGFR1-3 and inhibited recombinant FGFR kinase activity in vitro and suppressed FGFR signaling and growth in tumor cell lines with deregulated FGFR expression [47]. After treatment of GC cell-lines (SNU-16 and KATO III) with AZD4547, expression levels of phosphorylated FGFR2 and its downstream signaling molecules, such as phospholipase C-gamma, FRS2, ERK, and S6, were all reduced [48]. Furthermore, treatment with AZD4547 also dose-dependently increased the sub-G1 population of GC cells. AZD4547 inhibited tumor regression in FGFR2-amplified xenografts (SNU16) but not in nonamplified models (AZ521 and MGC803) in that study. In addition, antitumor efficacy was enhanced in vivo by combined chemotherapy with AZD4547 plus chemotherapeutic agents as compared with monotherapy.

Ponatinib (AP24534) was designed with a carbon-carbon triple bond to accommodate the T315I mutation in the ABL kinase domain [49]. Ponatinib potently inhibits the kinase activity of FGFR1-4 and had higher inhibitory activity in GC cells with FGFR2 amplification than did other FGFR inhibitors and inhibited the growth of SNU-16 xenograft tumors [50]. In addition, ponatinib potently inhibited cell proliferation and signaling in several cell lines of other cancers with FGFR mutation.
S49076, a potent inhibitor of FGFR1-3, MET, and AXL, inhibited the autophosphorylation of those receptors and the phosphorylation of FRS2 [51]. S49076 inhibited viability in SNU-16 cell lines and tumor growth in SNU-16 xenografts. Combined treatment with S49076 and bevacizumab, a VEGF inhibitor, enhanced the antitumor effect in other cancer xenografts.

Dovitinib (TKI258) is an oral multitargeted TKI of FGFR1-3, VEGFR, platelet-derived growth factor receptor (PDGFR), FMS-like tyrosine kinase 3 (FLT-3), KIT, and colony stimulating factor 1 . The potent growth inhibitory activity of dovitinib was specifically observed in FGFR2amplified GC cell lines (KATO-III and SNU-16) [33]. Dovitinib treatment decreased phosphorylation of FGFR2, Akt, and ERK and inhibited soft agar colony formation in FGFR2amplified GC cell lines, although additional factors might be required to induce apoptosis by dovitinib treatment. Dovitinib inhibited tumor growth in an FGFR2-amplified primary human GC xenograft model [33].

Small interfering RNA (siRNA), the intermediate product of the pathway of RNA interference, plays a key role in RNA silencing treatment. Silencing of FGFR expression by treatment with siRNA led to inhibition of proliferation and promotion of apoptosis accompanied by a reduction in VEGFR expression and a rise in caspase-3, an apoptosis-related protein, in an in vitro study [52]. In experimental in vivo studies using GC cells (MGC80-3), siRNA also suppressed the expression of FGFR and enhanced tumor shrinkage [52].

MicroRNAs ( $\mathrm{miR}$ ) negatively regulate protein expression by binding to protein-coding mRNAs and inhibiting translation. The $3^{\prime} \mathrm{UTR}$ of FGFR1 mRNA contains two putative binding sites of miR-133b [53]. Therefore, miR-133b reduced the protein expression of FGFR1. Furthermore, upregulation of FGFR1 expression was found to negatively correlate with miR-133b expression in several GC lines and GC tissues.

\section{Clinical Trials of FGFR-Targeted Treatment in GC}

Clinical trials of FGFR inhibitors for GC are summarized in Table 3. Several phase II trials of FGFR inhibitors are ongoing in GC. Dovitinib was evaluated in a phase I study of 35 solid tumors including 2 GCs [54]. Enrolled patients were treated in four intermittent (25-100 mg/day) and three continuous (100-175 mg/day) dosing cohorts. Dose-limiting toxicities were grade 3 hypertension in one patient in the $100 \mathrm{mg}$ continuous dosing cohort, grade 3 anorexia in a second patient at $175 \mathrm{mg}$, and grade 3 alkaline phosphatase elevation in a third patient at $175 \mathrm{mg}$. Unfortunately, neither patient with GC had stable disease for more than 4 months in this study. Nonetheless, three phase II studies of dovitinib are ongoing in GC. Dovitinib is being assessed as salvage monotherapy after failure of first- or second-line chemotherapy in patients with advanced or metastatic scirrhous GC in one study [55] and in patients with GC harboring FGFR2 amplification in another study [56]. Dovitinib was administered orally at $500 \mathrm{mg} /$ day on days 1 to 5 of 7-day repeated cycles in both studies. In the third study, divided into phase I and phase II, dovitinib is 
TABLE 3: Clinical trials of FGFR-targeting agents in GC.

\begin{tabular}{|c|c|c|c|c|c|c|}
\hline Agent & Target & Type of cancer & Phase & Combined regimen & Status & Reference \\
\hline \multirow[b]{2}{*}{ Dovitinib (TKI258) } & \multirow{2}{*}{$\begin{array}{c}\text { FGFR, VEGFR, PDGFR, } \\
\text { FLT-3, KIT, and CSF-1 }\end{array}$} & Gastric (scirrhous type) & II & None & Ongoing & {$[55]$} \\
\hline & & $\begin{array}{c}\text { Gastric (FGFR2 } \\
\text { amplification) }\end{array}$ & II & None & Ongoing & {$[56]$} \\
\hline \multirow[b]{2}{*}{ AZD4547 } & \multirow[b]{2}{*}{ FGFR and VEGFR } & Gastric & II & Docetaxel & Ongoing & {$[57]$} \\
\hline & & $\begin{array}{c}\text { Gastric (FGFR2 } \\
\text { amplification) }\end{array}$ & II & Paclitaxel & Ongoing & {$[58]$} \\
\hline
\end{tabular}

TABLE 4: Phase III clinical trials of FGFR-targeting agents.

\begin{tabular}{|c|c|c|c|c|c|c|}
\hline Agent & Target & Type of cancer & Phase & $\begin{array}{l}\text { Combined regimen } \\
\text { (comparative arm) }\end{array}$ & Status or result & Reference \\
\hline \multirow{3}{*}{$\begin{array}{l}\text { Cediranib } \\
(\text { AZD2171) }\end{array}$} & \multirow{3}{*}{ FGFR and VEGFR } & CRC & III & $\begin{array}{c}\text { FOLFOX or CAPOX } \\
\text { (FOLFOX or CAPOX }+ \\
\text { placebo })\end{array}$ & Negative on OS & [59] \\
\hline & & CRC & III & $\begin{array}{l}\text { FOLFOX (FOLFOX + } \\
\text { bevacizumab) }\end{array}$ & Negative on PFS & {$[60]$} \\
\hline & & NSLSC & III & $\begin{array}{l}\text { Carboplatin + paclitaxel } \\
(\text { carboplatin + paclitaxel } \\
\text { + placebo })\end{array}$ & $\begin{array}{l}\text { Negative } \\
\text { on PFS/OS }\end{array}$ & {$[61]$} \\
\hline \multirow{3}{*}{$\begin{array}{l}\text { Brivanib } \\
\text { (BMS582664) }\end{array}$} & \multirow{3}{*}{ FGFR and VEGFR } & $\begin{array}{c}\text { CRC (wild-type } \\
\text { KRAS) }\end{array}$ & III & $\begin{array}{l}\text { Cetuximab (cetuximab }+ \\
\text { placebo) }\end{array}$ & Negative on OS & {$[62]$} \\
\hline & & $\mathrm{HCC}$ & III & None (sorafenib) & Negative on OS & {$[63]$} \\
\hline & & HCC & III & None (placebo) & Negative on OS & {$[64]$} \\
\hline $\begin{array}{l}\text { Dovitinib } \\
\text { (TKI258) }\end{array}$ & $\begin{array}{c}\text { FGFR, VEGFR, PDGFR, } \\
\text { FLT-3, KIT, and CSF-1 }\end{array}$ & $\mathrm{RCC}$ & III & None (sorafenib) & Negative on PFS & {$[65]$} \\
\hline $\begin{array}{l}\text { Nintedanib } \\
\text { (BIBF1120) }\end{array}$ & $\begin{array}{l}\text { FGFR, VEGFR, PDGFR, } \\
\text { FLT-3, and LCK }\end{array}$ & NSCLC & III & $\begin{array}{c}\text { Docetaxel (docetaxel + } \\
\text { placebo) }\end{array}$ & Positive on PFS & {$[66]$} \\
\hline \multirow{2}{*}{$\begin{array}{l}\text { Lenvatinib } \\
\text { (E7080) }\end{array}$} & \multirow{2}{*}{$\begin{array}{l}\text { FGFR, VEGFR, and } \\
\text { PDGFR }\end{array}$} & HCC & III & None (sorafenib) & Ongoing & {$[68]$} \\
\hline & & Thyroid & III & None (placebo) & Ongoing & {$[69]$} \\
\hline $\begin{array}{l}\text { Orantinib } \\
\text { (TSU68) }\end{array}$ & $\begin{array}{l}\text { FGFR, VEGFR, and } \\
\text { PDGFR }\end{array}$ & HCC & III & None (placebo) & Suspended & {$[70]$} \\
\hline
\end{tabular}

CRC: colorectal cancer; NSCLC: non-small-cell lung cancer; HCC: hepatocellular carcinoma; RCC: renal cell carcinoma; FOLFOX: 5-fluorouracil + leucovorin + oxaliplatin; CAPOX: capecitabine + leucovorin + oxaliplatin; RFS: relapse-free survival; OS: overall survival.

being assessed in combination with docetaxel as second-line chemotherapy in patients with GC [57].

A phase II study of AZD4547, an oral TKI of both FGFR and VEGFR, is also ongoing to assess the efficacy and safety of AZD4547 monotherapy versus paclitaxel in patients with locally advanced or metastatic GC associated with FGFR2 polysomy or amplification [58]. AZD4547 was administered orally at $160 \mathrm{mg} /$ patients on days 1 to 14 of a 21-day cycle.

\section{Results of Clinical Trials of FGFR-Targeted Treatment in Various Cancers}

Phase III clinical trials in patients with other types of cancer are shown in Table 4. Cediranib (AZD2171) is an oral TKI of both FGFR and VEGFR. In one study of colorectal cancer, the addition of cediranib to standard first-line chemotherapy significantly prolonged PFS but not OS [59]. In the other study, the noninferiority of cediranib did not reach the predefined level of PFS as compared with bevacizumab [60]. No synergistic effect of cediranib was found in patients with nonsmall-cell lung carcinoma (NSCLC) [61]. Brivanib (BMS582664) is an oral TKI of both FGFR and VEGFR, and the addition of brivanib increased toxicity and did not improve OS as compared with cetuximab alone in patients with colorectal cancer with wild-type KRAS [62]. In addition, no significant effect of brivanib was found in unresectable hepatocellular carcinoma $[63,64]$. Dovitinib (TKI258) is an oral multitargeted TKI, including FGFR, and was not superior to sorafenib in metastatic renal cell carcinoma [65]. Nintedanib (BIBF1120) is an oral TKI of FGFR, VEGFR, PDGFR, FLT-3, and lymphocyte-specific protein tyrosine kinase and significantly prolonged PFS in combination with docetaxel in patients with NSCLC [66].

\section{Conclusions}

Aberrant activation of FGFR signaling pathway, especially FGFR2 amplification, is related to disease progression or poor survival in GC; thus FGFR-targeted therapy is considered 
promising. Unfortunately, the superiority of multitargeted TKIs, including those with FGFR inhibitory activity, to standard chemotherapy has not been demonstrated in most phase III clinical trials in other malignancies. However, TKIs were evaluated as VEGFR inhibitors, but not FGFR inhibitors, in those studies. FGFR inhibitors were shown to have higher antitumor activity against FGFR2-amplified tumors than against nonamplified tumors in preclinical studies $[32,33$, $38,40-42,46,48,50,51]$. Therefore, ongoing clinical trials of dovitinib or AZD4547 in patients with FGFR2-amplified GC are expected to show positive results. Scirrhous gastric cancer is known to be refractory to intensive treatment and to carry a poor prognosis; however, FGFR2 amplification is found in cell lines originating from scirrhous GC, such as KATO-III, SNU-16, and OCUM-2M. FGFR inhibitors may be a promising treatment for scirrhous GC and are now being evaluated in clinical trials. On the other hand, intratumoral heterogeneity of FGFR2 amplification has been found in GC samples [32]. Intratumoral heterogeneity of HER2 was also detected in GC, and the expression levels of primary lesions may not be consistent with those of metastatic sites. Intratumoral heterogeneity can be a critical issue for a single molecular-targeted treatment [67].

Amplification of other FGFRs has not been found in GC; however, overexpression of FGFR1 and FGFR4 or single nucleotide polymorphism of FGFR4 appears to be associated with tumor progression or survival [19, 23, 36]. Preclinical studies evaluating other FGFRs in GC remain scant. FGFR2 amplification was detected in only $1.8 \%$ to $7.3 \%$ of patients with GC, regardless of ethnic group; therefore, only a small subgroup of patients with GC can potentially benefit from FGFR2-targeted therapy alone. The development of FGFR inhibitors against tumors with overexpression not only of FGFR2 but also of FGFR1 or FGFR4 is likely to enhance potential treatment benefits in patients with GC.

\section{Conflict of Interests}

The authors declare that there is no conflict of interests regarding the publication of this paper.

\section{References}

[1] A. Jemal, F. Bray, M. M. Center, J. Ferlay, E. Ward, and D. Forman, "Global cancer statistics," A Cancer Journal for Clinicians, vol. 61, no. 2, pp. 69-90, 2011.

[2] W. Koizumi, H. Narahara, T. Hara et al., "S-1 plus cisplatin versus S-1 alone for first-line treatment of advanced gastric cancer (SPIRITS trial): a phase III trial," The Lancet Oncology, vol. 9, no. 3, pp. 215-221, 2008.

[3] W. Koizumi, Y. H. Kim, M. Fujii et al., "Addition of docetaxel to S-1 without platinum prolongs survival of patients with advanced gastric cancer: a randomized study (START)," Journal of Cancer Research and Clinical Oncology, vol. 140, no. 2, pp. 319328, 2014.

[4] D. Cunningham, N. Starling, S. Rao et al., "Capecitabine and oxaliplatin for advanced esophagogastric cancer," The New England Journal of Medicine, vol. 358, no. 1, pp. 36-46, 2008.

[5] Y. J. Bang, E. van Cutsem, A. Feyereislova et al., “ Trastuzumab in combination with chemotherapy versus chemotherapy alone for treatment of HER2-positive advanced gastric or gastrooesophageal junction cancer ( ToGA ): a phase 3, open-label, randomised controlled trial," The Lancet, vol. 376, no. 9742, pp. 687-697, 2010.

[6] F. Lordick, Y.-K. Kang, H.-C. Chung et al., "Capecitabine and cisplatin with or without cetuximab for patients with previously untreated advanced gastric cancer (EXPAND): a randomised, open-label phase 3 trial," The Lancet Oncology, vol. 14, no. 6, pp. 490-499, 2013.

[7] T. Waddell, I. Chau, D. Cunningham et al., "Epirubicin, oxaliplatin, and capecitabine with or without panitumumab for patients with previously untreated advanced oesophagogastric cancer (REAL3): a randomised, open-label phase 3 trial," The Lancet Oncology, vol. 14, no. 6, pp. 481-489, 2013.

[8] T. Satoh, R.-H. Xu, H. C. Chung et al., "Lapatinib plus paclitaxel versus paclitaxel alone in the second-line treatment of HER2-amplified advanced gastric cancer in Asian populations: TyTAN-a randomized, phase III study," Journal of Clinical Oncology, vol. 32, no. 19, pp. 2039-2049, 2014.

[9] A. Ohtsu, M. A. Shah, E. van Cutsem et al., "Bevacizumab in combination with chemotherapy as first-line therapy in advanced gastric cancer: a randomized, double-blind, placebocontrolled phase III study," Journal of Clinical Oncology, vol. 29, no. 30, pp. 3968-3976, 2011.

[10] C. S. Fuchs, J. Tomasek, C. J. Yong et al., "Ramucirumab monotherapy for previously treated advanced gastric or gastrooesophageal junction adenocarcinoma (REGARD): an international, randomised, multicentre, placebo-controlled, phase 3 trial," The Lancet, vol. 383, no. 9911, pp. 31-39, 2014.

[11] H. Wilke, K. Muro, E. van Custem et al., "Ramucirumab plus paclitaxel versus placebo plus paclitaxel in patients with previously treated advanced gastric or gastro-oesophageal junction adenocarcinoma (RAINBOW): a double-blind, randomised phase 3 trial," The Lancet Oncology, vol. 15, no. 11, pp. 1224-1235, 2014.

[12] T. Iveson, R. C. Donehower, I. Davidenko et al., "Rilotumumab in combination with epirubicin, cisplatin, and capecitabine as first-line treatment for gastric or oesophagogastric junction adenocarcinoma: an open-label, dose de-escalation phase $1 \mathrm{~b}$ study and a double-blind, randomised phase 2 study," The Lancet Oncology, vol. 15, no. 9, pp. 1007-1018, 2014.

[13] D. E. Johnson and L. T. Williams, "Structural and functional diversity in the FGF receptor multigene family," Advances in Cancer Research, vol. 60, pp. 1-41, 1993.

[14] V. P. Eswarakumar, I. Lax, and J. Schlessinger, "Cellular signaling by fibroblast growth factor receptors," Cytokine and Growth Factor Reviews, vol. 16, no. 2, pp. 139-149, 2005.

[15] D. M. Ornitz, J. Xu, J. S. Colvin et al., "Receptor specificity of the fibroblast growth factor family," The Journal of Biological Chemistry, vol. 271, no. 25, pp. 15292-15297, 1996.

[16] X. Zhang, O. A. Ibrahimi, S. K. Olsen, H. Umemori, M. Mohammadi, and D. M. Ornitz, "Receptor specificity of the fibroblast growth factor family: the complete mammalian FGF family," The Journal of Biological Chemistry, vol. 281, no. 23, pp. $15694-$ 15700, 2006.

[17] A. Beenken and M. Mohammadi, "The FGF family: biology, pathophysiology and therapy," Nature Reviews Drug Discovery, vol. 8, no. 3, pp. 235-253, 2009.

[18] N. Turner and R. Grose, "Fibroblast growth factor signalling: from development to cancer," Nature Reviews Cancer, vol. 10, no. 2, pp. 116-129, 2010. 
[19] H. Murase, M. Inokuchi, Y. Takagi, K. Kato, K. Kojima, and K. Sugihara, "Prognostic significance of the co-overexpression of fibroblast growth factor receptors 1, 2 and 4 in gastric cancer," Molecular Clinical Oncology, vol. 2, no. 4, pp. 509-517, 2014.

[20] T. Toyokawa, M. Yashiro, and K. Hirakawa, "Co-expression of keratinocyte growth factor and K-sam is an independent prognostic factor in gastric carcinoma," Oncology Reports, vol. 21, no. 4, pp. 875-880, 2009.

[21] Y. Hattori, H. Itoh, S. Uchino et al., "Immunohistochemical detection of K-sam protein in stomach cancer," Clinical Cancer Research, vol. 2, no. 8, pp. 1373-1381, 1996.

[22] A. K. Nagatsuma, M. Aizawa, T. Kuwata et al., "Expression profiles of HER2, EGFR, MET and FGFR2 in a large cohort of patients with gastric adenocarcinoma," Gastric Cancer, 2014.

[23] Y.-W. Ye, X. Zhang, Y. Zhou et al., “The correlations between the expression of FGFR4 protein and clinicopathological parameters as well as prognosis of gastric cancer patients," Journal of Surgical Oncology, vol. 106, no. 7, pp. 872-879, 2012.

[24] E.-Y. Shin, B.-H. Lee, J.-H. Yang et al., "Up-regulation and coexpression of fibroblast growth factor receptors in human gastric cancer," Journal of Cancer Research and Clinical Oncology, vol. 126, no. 9, pp. 519-528, 2000.

[25] H. K. Kim, I. J. Choi, C. G. Kim et al., “Three-gene predictor of clinical outcome for gastric cancer patients treated with chemotherapy," Pharmacogenomics Journal, vol. 12, no. 2, pp. 119-127, 2012.

[26] H. Tsujimoto, H. Sugihara, A. Hagiwara, and T. Hattori, "Amplification of growth factor receptor genes and DNA ploidy pattern in the progression of gastric cancer," Virchows Archiv, vol. 431, no. 6, pp. 383-389, 1997.

[27] D.-F. Peng, H. Sugihara, K.-I. Mukaisho, Y. Tsubosa, and T. Hattori, "Alterations of chromosomal copy number during progression of diffuse-type gastric carcinomas: metaphase- and array-based comparative genomic hybridization analyses of multiple samples from individual tumours," The Journal of Pathology, vol. 201, no. 3, pp. 439-450, 2003.

[28] G. Betts, H. Valentine, S. Pritchard et al., "FGFR2, HER2 and cMet in gastric adenocarcinoma: detection, prognostic significance and assessment of downstream pathway activation," Virchows Archiv, vol. 464, no. 2, pp. 145-156, 2014.

[29] E.-J. Jung, E.-J. Jung, S. Y. Min, M. A. Kim, and W. H. Kim, "Fibroblast growth factor receptor 2 gene amplification status and its clinicopathologic significance in gastric carcinoma," Human Pathology, vol. 43, no. 10, pp. 1559-1566, 2012.

[30] K. Das, B. Gunasegaran, I. B. Tan, N. Deng, K. H. Lim, and P. Tan, "Mutually exclusive FGFR2, HER2, and KRAS gene amplifications in gastric cancer revealed by multicolour FISH," Cancer Letters, vol. 353, no. 2, pp. 167-175, 2014.

[31] X. Su, P. Zhan, P. R. Gavine et al., "FGFR2 amplification has prognostic significance in gastric cancer: results from a large international multicentre study," British Journal of Cancer, vol. 110, no. 4, pp. 967-975, 2014.

[32] K. Matsumoto, T. Arao, T. Hamaguchi et al., "FGFR2 gene amplification and clinicopathological features in gastric cancer," British Journal of Cancer, vol. 106, no. 4, pp. 727-732, 2012.

[33] N. Deng, L. K. Goh, H. Wang et al., "A comprehensive survey of genomic alterations in gastric cancer reveals systematic patterns of molecular exclusivity and co-occurrence among distinct therapeutic targets," Gut, vol. 61, no. 5, pp. 673-684, 2012.
[34] K. Wang, S. T. Yuen, J. Xu et al., "Whole-genome sequencing and comprehensive molecular profiling identify new driver mutations in gastric cancer," Nature Genetics, vol. 46, no. 6, pp. 573$582,2014$.

[35] J.-H. Jang, K.-H. Shin, and J.-G. Park, "Mutations in fibroblast growth factor receptor 2 and fibroblast growth factor receptor 3 genes associated with human gastric and colorectal cancers," Cancer Research, vol. 61, no. 9, pp. 3541-3543, 2001.

[36] Y. Ye, Y. Shi, Y. Zhou et al., "The fibroblast growth factor receptor-4 Arg388 allele is associated with gastric cancer progression," Annals of Surgical Oncology, vol. 17, no. 12, pp. 33543361, 2010.

[37] M. Kakiuchi, T. Nishizawa, H. Ueda et al., "Recurrent gain-offunction mutations of RHOA in diffuse-type gastric carcinoma," Nature Genetics, vol. 46, no. 6, pp. 583-587, 2014.

[38] K. Kunii, L. Davis, J. Gorenstein et al., "FGFR2-amplified gastric cancer cell lines require FGFR2 and Erbb3 signaling for growth and survival," Cancer Research, vol. 68, no. 7, pp. 2340-2348, 2008.

[39] S. Park, J.-H. Kim, and J.-H. Jang, "Aberrant hypermethylation of the FGFR2 gene in human gastric cancer cell lines," Biochemical and Biophysical Research Communications, vol. 357, no. 4, pp. 1011-1015, 2007.

[40] W.-M. Zhao, L. Wang, H. Park et al., "Monoclonal antibodies to fibroblast growth factor receptor 2 effectively inhibit growth of gastric tumor xenografts," Clinical Cancer Research, vol. 16, no. 23, pp. 5750-5758, 2010.

[41] A. Bai, K. Meetze, N. Y. Vo et al., "GP369, an FGFR2-IIIbspecific antibody, exhibits potent antitumor activity against human cancers driven by activated FGFR2 signaling," Cancer Research, vol. 70, no. 19, pp. 7630-7639, 2010.

[42] M. Mohammadi, G. McMahon, L. Sun et al., "Structures of the tyrosine kinase domain of fibroblast growth factor receptor in complex with inhibitors," Science, vol. 276, no. 5314, pp. 955960, 1997.

[43] M. Koziczak, T. Holbro, and N. E. Hynes, "Blocking of FGFR signaling inhibits breast cancer cell proliferation through downregulation of D-type cyclins," Oncogene, vol. 23, no. 20, pp. 35013508, 2004.

[44] K. Nakamura, M. Yashiro, T. Matsuoka et al., "A novel molecular targeting compound as K-samII /FGF-R2 phosphorylation inhibitor, Ki23057, for Scirrhous gastric cancer," Gastroenterology, vol. 131, no. 5, pp. 1530-1541, 2006.

[45] S. R. Wedge, J. Kendrew, L. F. Hennequin et al., "AZD2171: a highly potent, orally bioavailable, vascular endothelial growth factor receptor-2 tyrosine kinase inhibitor for the treatment of cancer," Cancer Research, vol. 65, no. 10, pp. 4389-4400, 2005.

[46] M. Takeda, T. Arao, H. Yokote et al., "AZD2171 shows potent antitumor activity against gastric cancer over-expressing fibroblast growth factor receptor $2 /$ keratinocyte growth factor receptor," Clinical Cancer Research, vol. 13, no. 10, pp. 3051-3057, 2007.

[47] P. R. Gavine, L. Mooney, E. Kilgour et al., "AZD4547: an orally bioavailable, potent, and selective inhibitor of the fibroblast growth factor receptor tyrosine kinase family," Cancer Research, vol. 72, no. 8, pp. 2045-2056, 2012.

[48] L. Xie, X. Su, L. Zhang et al., "FGFR2 gene amplification in gastric cancer predicts sensitivity to the selective FGFR inhibitor AZD4547," Clinical Cancer Research, vol. 19, no. 9, pp. 25722583, 2013.

[49] S. M. Hoy, "Ponatinib: a review of its use in adults with chronic myeloid leukaemia or philadelphia chromosome-positive acute 
lymphoblastic leukaemia," Drugs, vol. 74, no. 7, pp. 793-806, 2014.

[50] J. M. Gozgit, M. J. Wong, L. Moran et al., "Ponatinib (AP24534), a multitargeted pan-FGFR inhibitor with activity in multiple FGFR-amplified or mutated cancer models," Molecular Cancer Therapeutics, vol. 11, no. 3, pp. 690-699, 2012.

[51] M. F. Burbridge, C. J. Bossard, C. Saunier et al., "S49076 is a novel kinase inhibitor of MET, AXL, and FGFR with strong preclinical activity alone and in association with bevacizumab," Molecular Cancer Therapeutics, vol. 12, no. 9, pp. 1749-1762, 2013.

[52] D. Zhou, X. Jiang, W. Ding et al., "siRNA-participated chemotherapy: an efficient and specific therapeutic against gastric cancer," Journal of Cancer Research and Clinical Oncology, vol. 139, no. 12, pp. 2057-2070, 2013.

[53] D. Wen, S. Li, F. Ji et al., "MiR-133b acts as a tumor suppressor and negatively regulates FGFR1 in gastric cancer," Tumor Biology, vol. 34, no. 2, pp. 793-803, 2013.

[54] D. Sarker, R. Molife, T. R. J. Evans et al., "A phase I pharmacokinetic and pharmacodynamic study of TKI258, an oral, multitargeted receptor tyrosine kinase inhibitor in patients with advanced solid tumors," Clinical Cancer Research, vol. 14, no. 7, pp. 2075-2081, 2008.

[55] The U.S. National Institutes of Health, ClinicalTrials.gov, NCT01576380, https:/clinicaltrials.gov/ct2/show/NCT01576380.

[56] The U.S. National Institutes of Health, ClinicalTrials.gov, NCT01719549, https:/clinicaltrials.gov/ct2/show/NCT01719549.

[57] The U.S. National Institutes of Health, ClinicalTrials.gov, NCT01921673, https://clinicaltrials.gov/ct2/show/NCT01921673.

[58] The U.S. National Institutes of Health, ClinicalTrials.gov, NCT01457846, https:/clinicaltrials.gov/ct2/show/NCT01457846.

[59] P. M. Hoff, A. Hochhaus, B. C. Pestalozzi et al., "Cediranib plus FOLFOX/CAPOX versus placebo plus FOLFOX/CAPOX in patients with previously untreated metastatic colorectal cancer: a randomized, double-blind, phase III study (HORIZON II)," Journal of Clinical Oncology, vol. 30, no. 29, pp. 3596-3603, 2012.

[60] H.-J. Schmoll, D. Cunningham, A. Sobrero et al., "Cediranib with mFOLFOX6 versus bevacizumab with mFOLFOX6 as first-line treatment for patients with advanced colorectal cancer: a double-blind, randomized phase III study (HORIZON III)," Journal of Clinical Oncology, vol. 30, no. 29, pp. 3588-3595, 2012.

[61] S. A. Laurie, B. J. Solomon, L. Seymour et al., "Randomised, double-blind trial of carboplatin and paclitaxel with daily oral cediranib or placebo in patients with advanced non-small cell lung cancer: NCIC Clinical Trials Group study BR29," European Journal of Cancer, vol. 50, no. 4, pp. 706-712, 2014.

[62] L. L. Siu, J. D. Shapiro, D. J. Jonker et al., "Phase III randomized, placebo-controlled study of cetuximab plus brivanib alaninate versus cetuximab plus placebo in patients with metastatic, chemotherapy-refractory, wild-type K-RAS colorectal carcinoma: the NCIC Clinical Trials Group and AGITG CO.20 Trial," Journal of Clinical Oncology, vol. 31, no. 19, pp. 2477-2484, 2013.

[63] P. J. Johnson, S. Qin, J.-W. Park et al., "Brivanib versus sorafenib as first-line therapy in patients with unresectable, advanced hepatocellular carcinoma: results from the randomized phase III BRISK-FL study," Journal of Clinical Oncology, vol. 31, no. 28, pp. 3517-3524, 2013.

[64] J. M. Llovet, T. Decaens, J.-L. Raoul et al., "Brivanib in patients with advanced hepatocellular carcinoma who were intolerant to sorafenib or for whom sorafenib failed: results from the randomized phase III BRISK-PS study," Journal of Clinical Oncology, vol. 31, no. 28, pp. 3509-3516, 2013.

[65] R. J. Motzer, C. Porta, N. J. Vogelzang et al., "Dovitinib versus sorafenib for third-line targeted treatment of patients with metastatic renal cell carcinoma: an open-label, randomised phase 3 trial," The Lancet Oncology, vol. 15, no. 3, pp. 286-296, 2014.

[66] M. Reck, R. Kaiser, A. Mellemgaard et al., "Docetaxel plus nintedanib versus docetaxel plus placebo in patients with previously treated non-small-cell lung cancer (LUME-Lung 1): a phase 3, double-blind, randomised controlled trial," The Lancet Oncology, vol. 15, no. 2, pp. 143-155, 2014.

[67] Y. Nishida, T. Kuwata, H. Nitta et al., "A novel gene-protein assay for evaluating HER2 status in gastric cancer: simultaneous analyses of HER2 protein overexpression and gene amplification reveal intratumoral heterogeneity," Gastric Cancer, 2014.

[68] The U.S. National Institutes of Health, ClinicalTrials.gov, NCT01761266, https://clinicaltrials.gov/ct2/show/NCT01761266.

[69] The U.S. National Institutes of Health, ClinicalTrials.gov, NCT01321554, https:/clinicaltrials.gov/ct2/show/NCT01321554.

[70] The U.S. National Institutes of Health, ClinicalTrials.gov, NCT01465464, https://clinicaltrials.gov/ct2/show/NCT01465464. 


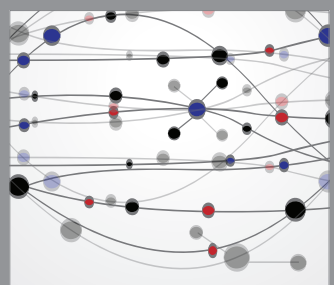

The Scientific World Journal
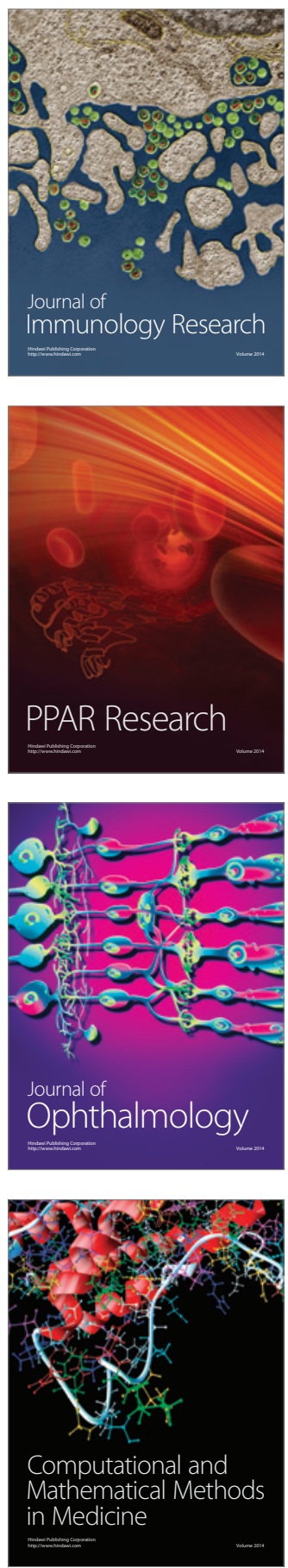

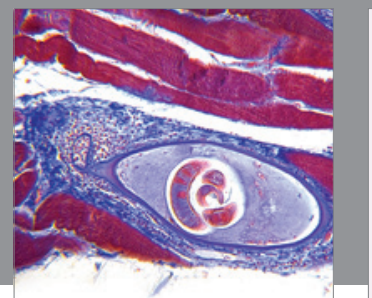

Gastroenterology

Research and Practice
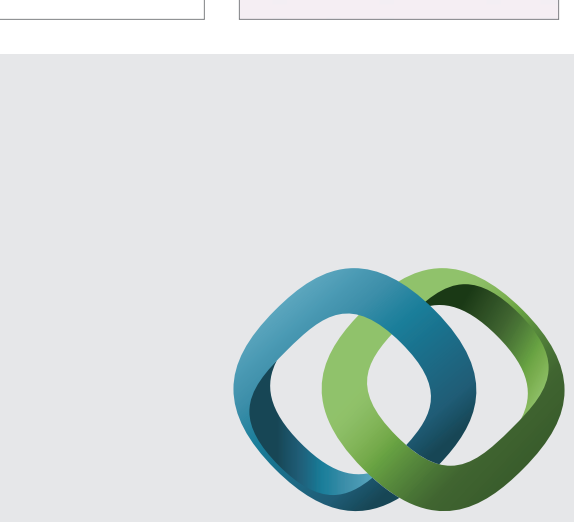

\section{Hindawi}

Submit your manuscripts at

http://www.hindawi.com
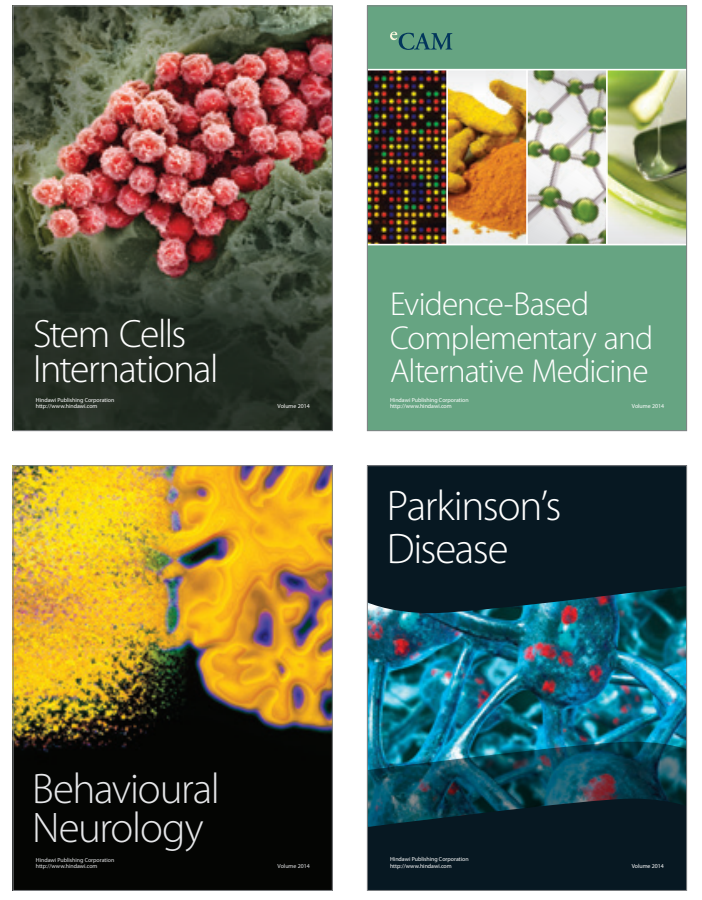
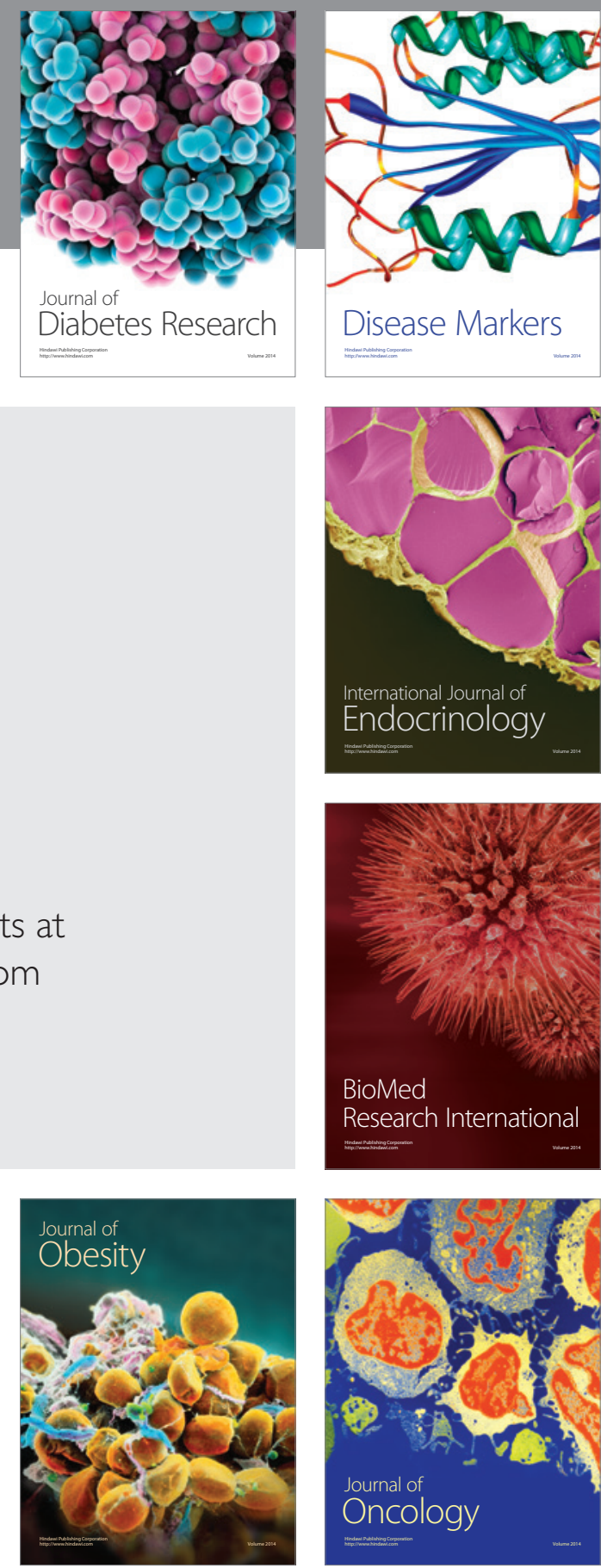

Disease Markers
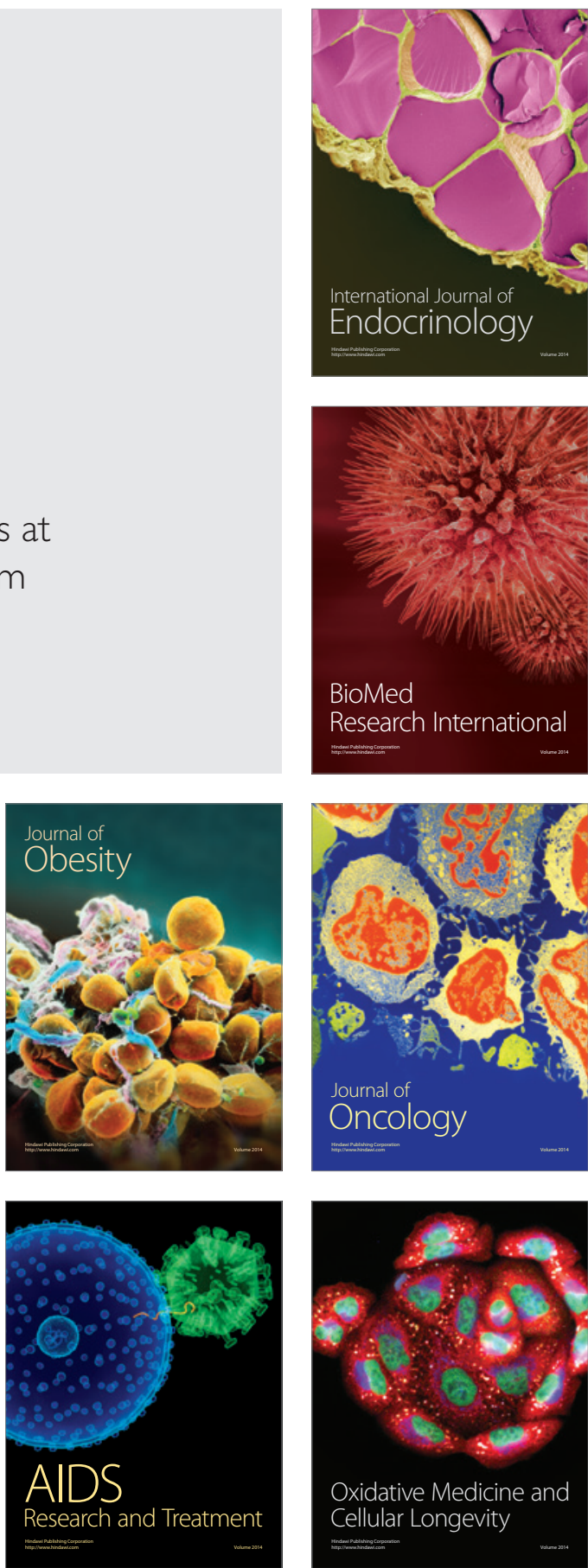